\title{
Proliferation and osteogenic activity of fibroblasts induced with fibronectin
}

\author{
W.-H. Zhang, X.-L. Li, Y. Guo and Y. Zhang \\ Tianjin Hospital, Tianjin, China
}

\begin{abstract}
The aim of this study was to determine the proliferation and osteogenic activity of fibroblasts induced with fibronectin and their possible dose-dependent relationship. The fibroblasts obtained by tissue explants adherent method were induced with fibronectin at different concentrations of $0,10,20,40,60$, and $80 \mu \mathrm{g} / \mathrm{mL}$ for 14 days. The ${ }^{3} \mathrm{H}$-thymidine and ${ }^{3} \mathrm{H}$-proline incorporation test was used to evaluate the synthesis of DNA and collagen by fibroblasts, respectively. The mineralized nodules and osteocalcin secretion, as vital osteogenic indicators, were detected with tetracycline labeling and ${ }^{125}$-labeled competitive immunoassay, respectively. Fibronectin significantly increased the synthesis of DNA and collagen by fibroblasts, especially at the concentration of $40 \mu \mathrm{g} / \mathrm{mL}(\mathrm{P}<0.05)$. The increased secretion of osteocalcin in the supernatant was also statistically significant at the concentration of $40 \mu \mathrm{g} / \mathrm{mL}(\mathrm{P}<0.05)$. The mineralized nodules with trabecula-like structure derived from induced fibroblasts were positive for tetracycline labeling. The granulation tissue-derived fibroblasts induced with fibronectin exhibited increased proliferative, functional and osteogenic potential. Fibroblasts are considered a possible in situ stem cell in tissue engineering.
\end{abstract}

Key words: Fibroblast; Fibronectin; Proliferation; Osteogenesis

\section{Introduction}

The infectious soft tissue and bone defects induced by trauma is often followed by bone non-union and osteolysis and has been a critical problem to be solved by orthopedic surgeons. These patients experience poor limb function and decreased life quality. Most orthopedic surgeons make great efforts to treat infectious soft tissue and bone defects using Western medicine. The first step is to reconstruct the soft tissue coverage of the defect area with flaps rich in blood supply, aiming to control infection with the assistance of efficient antibiotics. Secondarily, bone graft and rigid internal fixation are used to treat bone nonunion $(1,2)$. However, the results are not certain.

In the field of traditional Chinese medicine, the medicinal herbal extract named ShengJi Ointment (Tianjin Hospital, Tianjin, China) is applied to the surface of infectious soft tissue and bone defect. With time, granulation tissue exhibits growth and re-epithelization, and gradually covers the soft tissue defect. More interestingly, the island-shaped mineral-containing granulation tissue can be seen in the bone defect area, which gradually fuses and links the fragments of the fracture. It simultaneously repairs the infectious soft tissue and the bone defect. In the procedure, the secretion from the wound area, derived from the interaction of the local tissue and ShengJi Ointment, is fester-like and thought to play an important part in the healing. What could be responsible for the mineralization of the granulation tissue in the bone defect area? It is known that the main cell component of the granulation tissue is the fibroblast and the main biomolecule of the fester-like secretion is fibronectin (3). Therefore, our experiment was designed to determine whether the granulation tissue-derived fibroblasts show osteogenic activity when induced with fibronectin, and to determine their possible dose-dependent relationship in the proliferation of fibroblasts and osteogenesis.

\section{Material and Methods}

\section{Animal experiments and fibroblasts isolation}

A circular full-thickness skin defect, with a diameter of $2 \mathrm{~cm}$, was made on the back of two healthy adult rabbits (New Zealand rabbits, Institute of Laboratory Animal Sciences, CAMS \& PUMC) under aseptic condition. After 3 to 5 days, granulation tissue appeared in the circular area of the skin defect. We acquired the granulation tissue and cut it into $1 \times 1 \mathrm{~mm}$ pieces. The fragments of granulation tissue were washed three times with Hanks solution (Invitrogen, USA), plated in DMEM (Invitrogen) supplemented with $10 \%$ fetal bovine serum (Gibco, USA) and $1 \%$ mycillin (Invitrogen), in a $50-\mathrm{mL}$ culture bottle, and incubated at $37^{\circ} \mathrm{C}$ with $5 \% \mathrm{CO}_{2}$. Adherent fibroblasts were

Correspondence: Y. Zhang: <yangzhangdoc@163.com> 
harvested using $0.25 \%$ trypsin-EDTA (Invitrogen), and re-plated at $1 \times 10^{5} / \mathrm{mL}$ in the medium described above.

All animal use protocols were reviewed and approved by the Animal Management Committee of Tianjin City (China).

\section{Fibroblast culture}

Passage 3 fibroblasts were plated at $2 \times 10^{4}$ cells per well in a 24 -well plate and incubated at $37^{\circ} \mathrm{C}$ with $5 \% \mathrm{CO}_{2}$. After the cells adhered overnight, fibronectin (Sigma, USA) was added to the medium at the following concentrations: 0 (control group), 10, 20, 40, 60, and $80 \mu \mathrm{g} / \mathrm{mL}$. Cells were incubated at $37^{\circ} \mathrm{C}$ for 14 days, with three wells for each group. The medium containing fibronectin was regarded as a conditioned culture. The medium of each group was replaced every 3 days.

\section{Cell morphology}

The changes in cell morphology, cell structure and mineralized nodule formation were visualized every day with hematoxylin and eosin (HE) staining using an inverted phase contrast microscope (Olympus, Japan).

\section{Mineralized nodule labeling with tetracycline}

Tetracycline staining was used to demonstrate mineralization. After 14-day culture, PBS solution (Invitrogen) containing tetracycline (Sigma) at $50 \mu \mathrm{g} / \mathrm{mL}$ was added to each well with incubation at $37^{\circ} \mathrm{C}$ for $1 \mathrm{~h}$. The cells were incubated for another $1 \mathrm{~h}$ with the above medium, washed twice with Hanks solution and fixed with $80 \%$ cold alcohol (Invitrogen). Cell mineralization was visualized with a fluorescence microscope (Olympus).

\section{Labeling with ${ }^{3} \mathrm{H}$-thymidine}

The proliferative capacity of fibroblasts was evaluated with the amount of DNA synthesis labeled with ${ }^{3} \mathrm{H}$-thymidine $\left({ }^{3} \mathrm{H}-\mathrm{TdR}\right.$; China Institute of Atomic Energy, China), namely the ${ }^{3} \mathrm{H}$-TdR incorporation test. After fibroblasts were cultured for 7 and 14 days, ${ }^{3} \mathrm{H}-\mathrm{TdR}$ at $9.25 \mathrm{kBq} / \mathrm{mL}$ $\left(1 \mathrm{Ci}=3.7 \times 10^{10} \mathrm{~Bq}\right)$ was added to the medium and incubated at $37^{\circ} \mathrm{C}$ for $24 \mathrm{~h}$. The cells were collected, washed, dried at $80^{\circ} \mathrm{C}$ and detected by a liquid scintillation counter (Perkin Elmer, USA) with the result reported as count per minute (cpm)

\section{Labeling with ${ }^{3} \mathrm{H}$-proline}

The amount of collagen synthesis labeled with ${ }^{3} \mathrm{H}$-proline (China Institute of Atomic Energy) was assessed by a liquid scintillation counter (Perkin Elmer) with the result reported as cpm. The method was the same as that performed for ${ }^{3} \mathrm{H}-\mathrm{TdR}$ detection.

\section{Osteocalcin assessment}

Osteocalcin is regarded as an important indicator of osteogenesis. The supernatant was collected to assess the amount of secreted osteocalcin with ${ }^{125}$-labeled competitive immunoassay, after fibroblasts were cultured for 4, 7, and 14 days. The procedures were performed according to the description of the osteocalcin kit (Invitrogen). The unit of measurement was $\mu \mathrm{g} / \mathrm{L}$.

\section{Statistical analysis}

Data are reported as means \pm SD for each group. Comparisons between groups were performed by one-way analysis of variance (ANOVA) with version 12.0 of Statistical Package of Social Sciences software (SPSS Inc., USA). $\mathrm{P}<0.05$ was considered to be statistically significant.

\section{Results}

\section{Cell morphology}

Passage 3 fibroblasts began to adhere after seeding for $2 \mathrm{~h}$. After $24 \mathrm{~h}$, all fibroblasts adhered and stretched (Figure 1). The control group fibroblasts looked spindleshaped, reached $100 \%$ fusion rate after 3 days and displayed a fingerprint-shaped order after 5 days of incubation (Figure 2). As days passed, fibroblasts proliferated slowly and dropped sporadically. When cultured for 14 days, fibroblasts had little mineralized nodules.

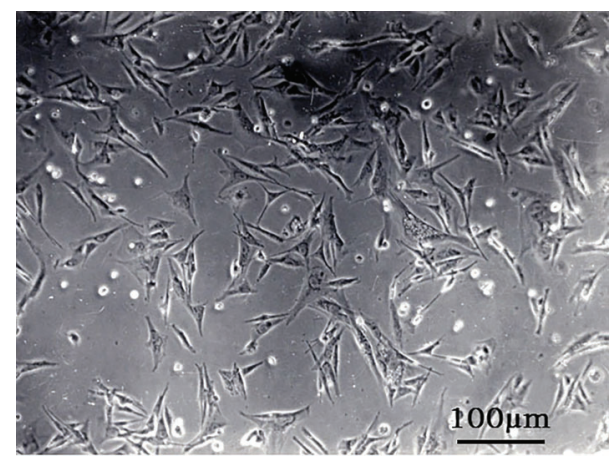

Figure 1. After seeding for $24 \mathrm{~h}$, passage 3 fibroblasts adhered and stretched. Phase contrast microscope, $\times 100$.

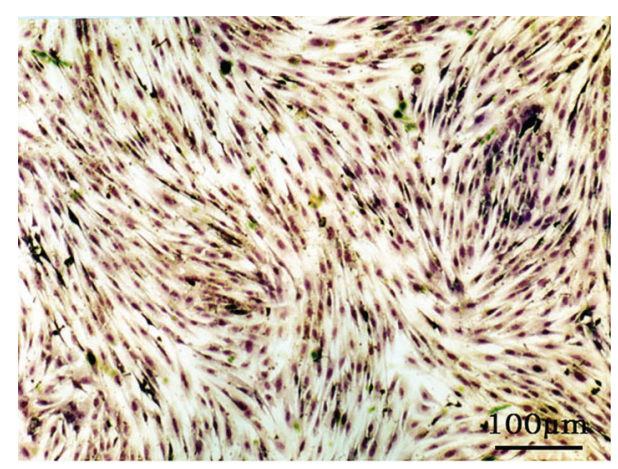

Figure 2. The control group fibroblasts reached confluence and displayed a fingerprint-shaped order at 5 days. HE staining, $\times 100$. 


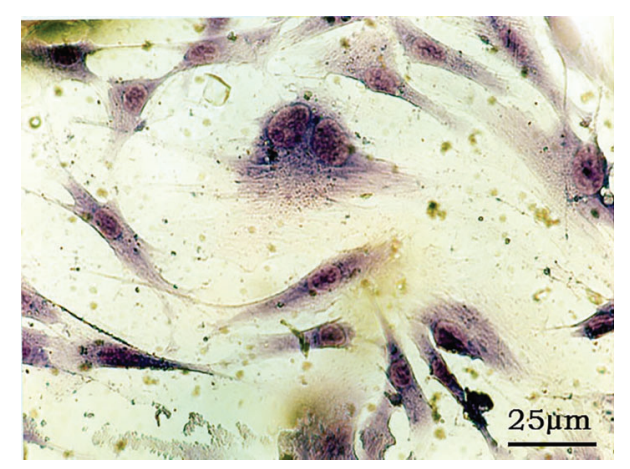

Figure 3. Fibroblasts induced with $40 \mu \mathrm{g} / \mathrm{mL}$ fibronectin had decentered nucleus and distinct particles in cytoplasm at 5 days. HE staining, $\times 200$.

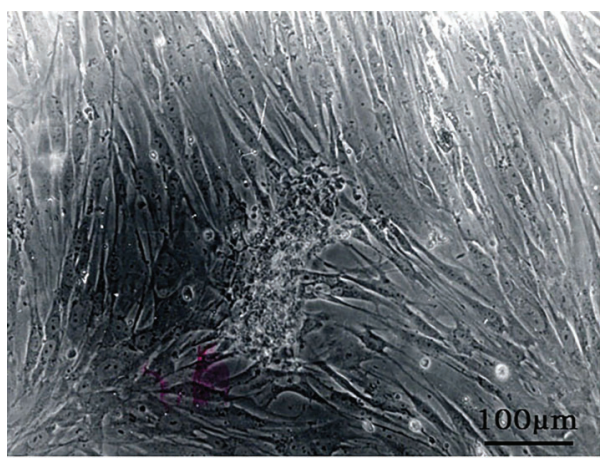

Figure 4. Nebulous extracellular secretions covered fibroblasts induced with $40 \mu \mathrm{g} / \mathrm{mL}$ fibronectin at 7 days. Phase contrast microscope, $\times 100$.

The fibroblasts in groups conditioned with fibronectin showed stronger proliferation compared with those of the control group. The fibroblasts looked triangle-shaped and exhibited obvious karyoschisis in the nucleolus after 3 days of culture. After culture for 5 days, fibroblasts had a decentered nucleus and distinct particles in cytoplasm (Figure 3). After 7 days, there were nebulous extracellular secretions covering cells (Figure 4). As days passed, nebulous secretions gathered and formed dark nodules (Figure 5). The dark nodules gradually fused and formed a trabecula-like structure.

\section{Mineralized nodule labeling with tetracycline}

The visualized dark nodules were positive for the tetracycline staining, indicating mineralization. Compared with the control group, there were more and larger golden nodules containing a trabecula-like structure in the conditioned groups, especially in the group with a fibronectin concentration of $40 \mu \mathrm{g} / \mathrm{mL}$ (Figure 6).

\section{Labeling with $\left({ }^{3} \mathrm{H}-\mathrm{TdR}\right)$}

The results of the ${ }^{3} \mathrm{H}-\mathrm{TdR}$ incorporation test indicated the amount of the fibroblast DNA synthesis. Fibronectin

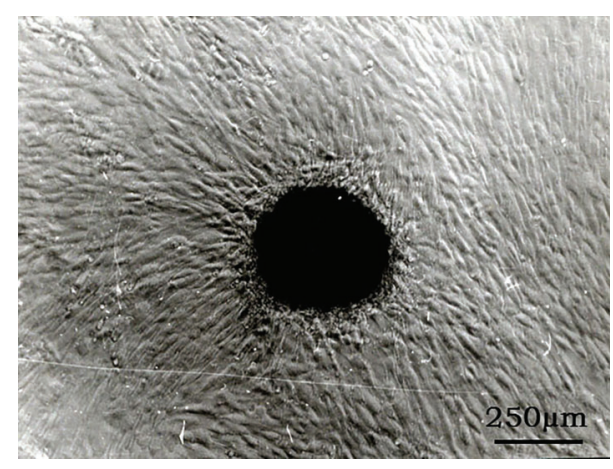

Figure 5. Dark tight nodules formed at 14 days in fibroblasts induced with $40 \mu \mathrm{g} / \mathrm{mL}$ fibronectin. Phase contrast microscope, $\times 100$.

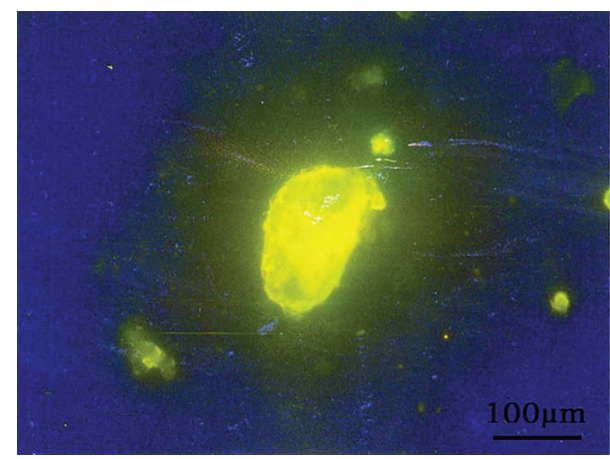

Figure 6. Tetracycline labeling for fibroblasts induced with $40 \mu \mathrm{g} / \mathrm{mL}$ fibronectin showing golden nodules, which had a trabecula-like structure. Fluorescence microscope, $\times 100$.

regulated the DNA synthesis of fibroblasts. The group with a fibronectin concentration of $60 \mu \mathrm{g} / \mathrm{mL}$ at 7 days and the group with a fibronectin concentration of $40 \mu \mathrm{g} / \mathrm{mL}$ at 14 days had significantly higher DNA synthesis $(P<0.05)$ compared with the other groups (Figure 7).

\section{Labeling with ${ }^{3} \mathrm{H}$-proline}

Fibronectin up-regulated the collagen synthesis of fibroblasts. The group with fibronectin concentration of $40 \mu \mathrm{g} / \mathrm{mL}$ peaked at 7 and 14 days $(P<0.05)$, the highest among all the groups (Figure 8).

\section{Osteocalcin assessment}

The increasing osteocalcin amount showed the osteogenesis capacity of fibroblasts induced by fibronectin. There was no statistical significance among groups at day $4(P>0.05)$. The group of $40 \mu \mathrm{g} / \mathrm{mL}$ fibronectin was statistically significant at day $7(\mathrm{P}<0.01)$ and day 14 $(P<0.05)$, compared with the other groups (Figure 9$)$.

\section{Discussion}

In this study, fibroblasts were obtained from the granulation tissue by tissue explants adherent method. Fibronectin 


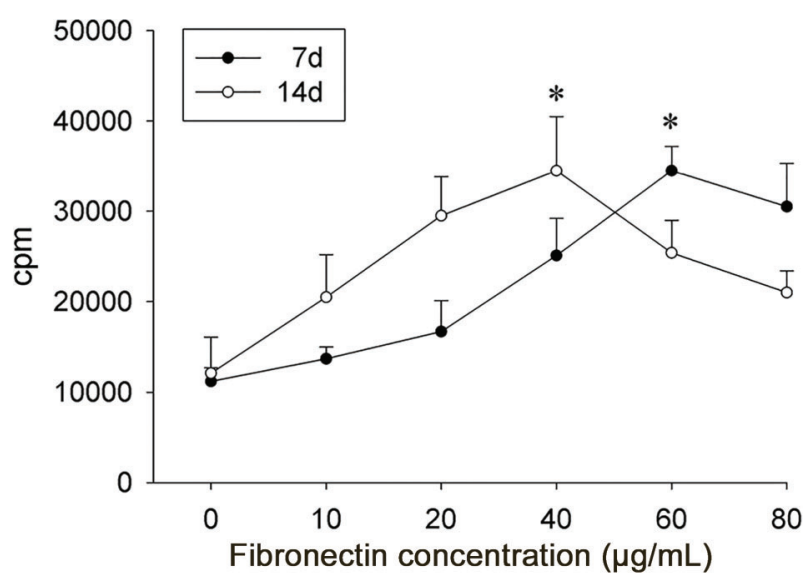

Figure 7. ${ }^{3} \mathrm{H}-\mathrm{TdR}$ incorporation test indicating that fibronectin regulated the DNA synthesis of fibroblasts. The $60 \mu \mathrm{g} / \mathrm{mL}$ fibronectin concentration at 7 days and the $40 \mu \mathrm{g} / \mathrm{mL}$ fibronectin at 14 days had significantly higher DNA synthesis compared to the other groups $\left({ }^{*} P<0.05\right.$, ANOVA). Data are reported as means $\pm S D$. cpm: counts per minute.

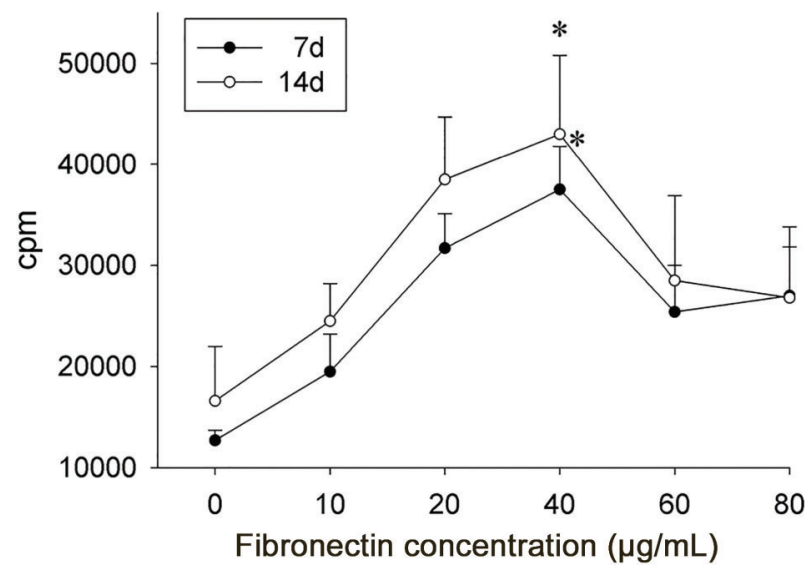

Figure 8. ${ }^{3} \mathrm{H}$-proline incorporation test showing that fibronectin up-regulated the collagen synthesis of fibroblasts. Collagen synthesis in the $40 \mu \mathrm{g} / \mathrm{mL}$ fibronectin group was significantly higher at 7 and 14 days than the other groups ( ${ }^{*} P<0.05$, ANOVA). Data are reported as means $\pm \mathrm{SD}$. cpm: counts per minute.

in different concentrations was used to induce fibroblasts, and the ability of proliferation and osteogenesis was evaluated. The ${ }^{3} \mathrm{H}$-TdR and ${ }^{3} \mathrm{H}$-proline incorporation test exhibited the high proliferative and functional capacity of fibroblasts, respectively. Fibronectin at $40 \mu \mathrm{g} / \mathrm{mL}$ dramatically up-regulated the proliferation and collagen synthesis of fibroblasts. The mineralized nodules and osteocalcin levels were vital osteogenic indicators. With the induction of fibronectin, fibroblasts looked triangle-shaped, proliferated, gathered with nebulous extracellular secretions and formed dark nodules ultimately. The nodules were positive for tetracycline-labeling and identified as mineralized nodules. Combined with the significantly increased

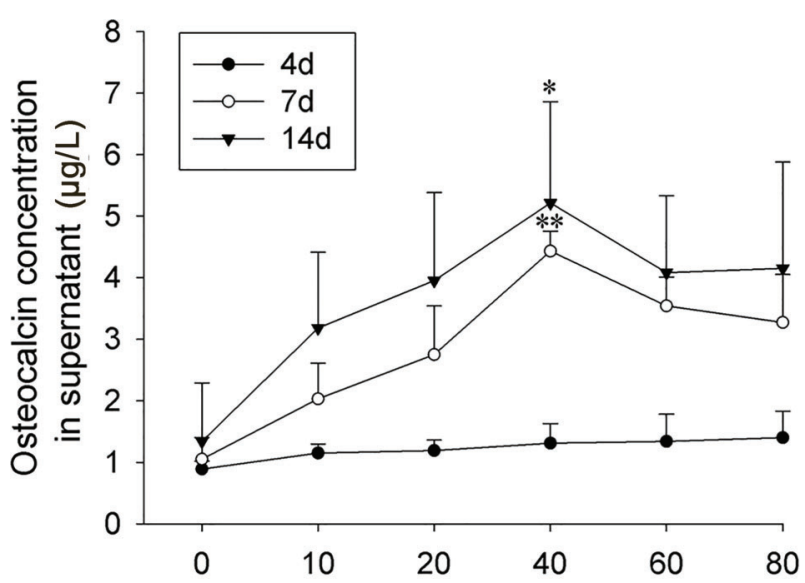

Fibronectin concentration $(\mu \mathrm{g} / \mathrm{mL})$

Figure 9. Osteocalcin concentration increased with culture time in all groups. The $40 \mu \mathrm{g} / \mathrm{mL}$ fibronectin was statistically significant at $7\left({ }^{* *} \mathrm{P}<0.01\right)$ and 14 days $\left({ }^{*} \mathrm{P}<0.05\right)$ compared to the other groups (ANOVA). Data are reported as means $\pm S D$.

osteocalcin levels, fibroblasts showed a definite osteogenic capacity when induced with fibronectin, especially at the concentration of $40 \mu \mathrm{g} / \mathrm{mL}$. In summary, fibroblasts induced with fibronectin showed a high potential of proliferation, function and osteogenesis.

Some reviews have reported that fibroblasts derived from the adventitia (4), cardiac $(5,6)$, burn scar (7) and normal skin (8) could be induced to myofibroblasts, which express $\alpha$-smooth muscle actin. Periodontal fibroblasts were considered to have the potential of osteoblastic differentiation with an osteogenic medium containing $50 \mathrm{mg} / \mathrm{mL}$ of ascorbic acid-2-phosphate and $10 \mathrm{mM}$ of $\beta$-glycerophosphate (9). Periodontal fibroblasts strongly expressed osteogenic genes such as ALP, Runx2, osterix and osteocalcin and formed mineralized nodules (10). The human dermal fibroblasts cultured on macroporous gelatin microcarriers encapsulated in platelet-rich plasma into three-dimensional constructs were successfully differentiated towards chondrogenic and osteogenic phenotypes using specific induction media (11). In 2005, Rieske et al. (12) reported that fibroblasts had some of the characteristics of stem cells, and could be induced to become neuroectodermal cells and perhaps even mature neurons. Moreover, the human vascular adventitial fibroblasts from pulmonary arteries, were cultured in appropriate media and showed osteogenic, adipogenic and myogenic differentiation (13).

Based on the above literature and our study on fibroblasts, we present the theory that fibroblasts have a potential of in situ pleuripotent stem cell. Under specific conditions, fibroblasts could exhibit pleuripotent differentiation in accordance with inductive factors. Mesenchymal stem cells (MSCs) are considered to be a promising source of stem cells in regenerative medicine. There has been evidence that MSCs could be induced to differentiate into 
fibroblasts with conditioned induction media (14). Perhaps fibroblasts are a kind of intermediate cell in the differentiation system from mesenchymal stem/progenitor cells to terminally differentiated cells, not strictly confined to differentiated fibrocytes.

The induced pluripotent stem (iPS) cells have also been extensively studied. Fully reprogrammed iPS cells display numerous properties similar to those of embryonic stem cells and exhibit the capacity of self-renewal and differentiation into three germ layers (15). Up to now, there are few documents that suggest the use of MSCs or iPS cells to treat infectious soft tissue and bone defects. A series of undergoing experiments at the molecular and cellular levels are rooted in clinical observations on the subject. Our experiment demonstrated the fibroblast capacity of proliferation and osteogenesis with the induction of fibronectins. More importantly, the results supported the clinical observations that the granulation tissue, whose main cellular component is the fibroblast, could treat infectious soft tissue and bone defects.

Why can fibroblasts survive in an infectious environment filled with virulent bacteria, such as staphylococcus aureus or/and pseudomonas aeruginosa, and display strong proliferation and osteogenesis? Although not tested in this study, a key factor could be the employment of the ShengJi Ointment, a Chinese herbal preparation.

\section{References}

1. Tiemann $A H$, Braunschweig $R$, Hofmann GO. Bone infections. Unfallchirurg 2012; 115: 480-488, doi: 10.1007/s00113012-2187-y.

2. Hart B. Osteomyelitis (refractory) with literature review supplement. Undersea Hyperb Med 2012; 39: 753-775.

3. Li XL, Han H, Shi YJ, Zhao FY, Xu EZ. A motive study of the capillary permeability during wound healing - First session of research program on "leaning on the pus to promote regeneration". China J Orthop Trauma 1994; 7: 5-7.

4. Shen W L, Gao PJ, Che ZQ, Ji KD, Yin M, Yan C, et al. NAD $(\mathrm{P}) \mathrm{H}$ oxidase-derived reactive oxygen species regulate angiotensin-II induced adventitial fibroblast phenotypic differentiation. Biochem Biophys Res Commun 2006; 339: 337-343, doi: 10.1016/j.bbrc.2005.10.207.

5. Yuko AN, Ping $D$, Yoshinori $H$, Jiang $Y$, Hamaoka $K$, Takamatsu T. Cx43 contributes to TGF- $\beta$ signaling to regulate differentiation of cardiac fibroblasts into myofibroblasts. Exper Cell Res 2009; 315: 1190-1199, doi: 10.1016/ j.yexcr.2008.12.021.

6. Yano T, Miura T, Ikeda Y, Matsuda E, Saito K, Miki T, et al. Intracardiac fibroblasts, but not bone marrow derived cells, are the origin of myofibroblasts in myocardial infarct repair. Cardiovasc Pathol 2005; 14: 241-246, doi: 10.1016/j.carpath. 2005.05.004.

7. Junker JP, Kratz C, Tollbäck A, Kratz G. Mechanical tension stimulates the transdifferentiation of fibroblasts into myofibroblasts in human burn scars. Burns 2008; 34: 942-946, doi: 10.1016/j.burns.2008.01.010.
Our preliminary work reported that the ShengJi Ointment and its fester-like secretions effectively enhanced capillary permeability of the local soft tissue and activated a monocyte-macrophage system that could efficiently secret various bioactive molecules, including fibronectins, not aiming at killing bacteria (16-18). Thus, we regarded ShengJi as an efficient biological agent, due to its immune modulation function. Although fibronectins play a vital role in adhesion, migration, chemotaxis and opsonization (19), many factors contribute to the local environment in a synergistic way. The employment of the Chinese herbal preparation as a promising biological agent and inductive factor is a novel strategy to induce the pluripotent stem cells in tissue engineering.

In conclusion, our experiment demonstrated that granulation tissue-derived fibroblasts induced with fibronectin exhibited increased proliferative, functional and osteogenic potential. Fibroblasts are considered a possible in situ stem cell in tissue engineering.

\section{Acknowledgments}

This work was supported by the Natural Science Funds of Tianjin (Grant No.11JCYBJC10200) and the Science and Technology Supporting Plan Key Project of Tianjin (Grant No.08ZCGYSF01300).
8. Huang CY, Fu X L, Liu J, Qi Y, Li S, Wang H. The involvement of integrin $\beta 1$ signaling in the migration and myofibroblastic differentiation of skin fibroblasts on anisotropic collagen-containing nanofibers. Biomaterials 2012; 33: 1791-1800, doi: 10.1016/j.biomaterials.2011.11.025.

9. Chen YC, Ninomiya T, Hosoya A, Hiraga T, Miyazawa $H$, Nakamura H. 1a,25-Dihydroxyvitamin D3 inhibits osteoblastic differentiation of mouse periodontal fibroblasts. Arch Oral Biol 2012; 57: 453-459, doi: 10.1016/j.archoralbio.2011. 10.005.

10. Hiraga T, Ninomiya T, Hosoya A, Takahashi M, Nakamura H. Formation of bone-like mineralized matrix by periodontal ligament cells in vivo: a morphological study in rats. $J$ Bone Miner Metab 2009; 27: 149-157, doi: 10.1007/s00774-0090039-9.

11. Sommar P, Pettersson S, Ness C, Johnson H, Kratz G, Junker JP. Engineering three-dimensional cartilage- and bone-like tissues using human dermal fibroblasts and macroporous gelatine microcarriers. J Plast Reconstr Aesthet Surg 2010; 63: 1036-1046, doi: 10.1016/j.bjps.2009.02.072.

12. Rieske P, Krynska B, Azizi SA. Human fibroblast-derived cell lines have characteristics of embryonic stem cells and cells of neuro-ectodermal origin. Differentiation 2005; 73: 474483, doi: 10.1111/j.1432-0436.2005.00050.x.

13. Hoshino A, Chiba H, Nagai K, Ishii G, Ochiai A. Human vascular adventitial fibroblasts contain mesenchymal stem/ progenitor cells. Biochem Biophys Res Commun 2008; 368: 305-310, doi: 10.1016/j.bbrc.2008.01.090. 
14. Han YF, Chai JK, Sun TJ, Li D, Tao R. Differentiation of human umbilical cord mesenchymal stem cells into dermal fibroblasts in vitro. Biochem Biophys Res Commun 2011; 413: 561-565, doi: 10.1016/j.bbrc.2011.09.001.

15. Takahashi K, Yamanaka S. Induction of pluripotent stem cells from mouse embryonic and adult fibroblast cultures by defined factors. Cell 2006;126: 663-676, doi: 10.1016/ j.cell.2006.07.024.

16. Li XL, Xu EZ, Shi YJ, Zhao FY. Phagocytic function and heterogeinicitic motive studies of surface wound healing Studies on the mechanism of Wei Nong Zhang Rou (2). China J Orthop Trauma 1995; 8: 8-11.
17. Li XL, Ji GY, Zhao FY, Shi YJ. Influence of immuno-activity of cellular oxidation metabolic function of the external used Chinese herb during wound healing - Study on the mechanism of Wei Nong Zhang Rou (3). China J Orthop Trauma 1995; 8: 9-11.

18. Li XL, Shi YJ, Xu EZ, Zhao FY. Motive study of fibrin binding protein in wound healing - Mechanism of Wei Nong Zhang Rou (IV) . China J Orthop Trauma 1995; 8: 10-12.

19. Wu D, Hong Q, Chen XM, Bo F, Aipingi L, Hang $L$, et al. Effective suppression of fibronectin synthesis by retrovirus delivered shRNA in rat cardiac fibroblasts. Sci China C Life Sci 2004; 47: 368-375, doi: 10.1360/03yc0126. 